\section{Reports of Societies}

\section{ROYAL SOCIETY OF MEDICINE}

\section{THE PRACTICE OF EXPERIMENTAL MEDICINE}

Professor R. A. McCance, president of the Section of Experimental Medicine, gave his inaugural address on December 12. It was entitled "The Practice of Experimental Medicine," and in it the speaker discussed the moral, ethical, and legal aspects of experimental work on human beings.

This was a delicate matter which demanded the serious thought and consideration of all those interested in medicine to-day. Professor McCance pointed out that, although Claude Bernard's writings entitled him to be regarded as the "father" of experimental medicine, John Hunter, Jenner, and Harvey had been brilliant exponents of it long before his time. The speaker then went on to a definition of the word " experiment." This should always involve a change of conditions with subsequent observation of the results. In one sense the attempt to cure an individual patient might be regarded as an experiment if the results were observed and followed up, but for the present discussion he preferred to extend the definition of the term to include anything done to a patient which was not generally accepted as being for his direct therapeutic benefit or as contributing to the diagnosis of his disease.

The study of man must always take first place in any department of experimental medicine, although much of the work could often be done on animals. Species differences sometimes introduced difficulties, however, and one of the attributes that made for success in experimental medicine was the instinct which told the investigator when to check his results on a second species and, above all, when to turn from animals to man.

\section{Experiments on Man}

If one wished to make experiments on animals in this country one had to comply with the law and obtain a licence from the Home Office, and no one would wish to do otherwise. Human beings were the only mammals for which a vivisection licence was not required; but the use of one's fellow-creatures as experimental animals raised all kinds of issues which had never been seriously faced.

Professor McCance discussed the position as regards both patients in hospital and normal healthy people. The experiment might be one of commission, and consist of making some test on a person for which there was no obvious or immediate need. Equally, it might be one of omission and consist of withholding treatment from a "control." How much should be done without asking the person's permission? No experiment could be carried out on healthy persons without their co-operation and consent, but when a person came into hospital many investigations and tests were made as part of the hospital routine, and it was easy, without upsetting the patient in any way, to make other simple tests which, although they might help to define the effects of disease on function in general, might be of no direct benefit to the particular patient concerned. If an investigator decided to ask a patient's permission to make some investigation on him, he was at once up against the difficulty of explaining exactly to a patient the nature and object of his work. He could tell the patient only in very general terms what his experiment would involve, explain the nature of the risk (if there was any), and ask for his co-operation. The whole responsibility always lay with the investigator. The patient trusted the staff of the hospital, of which the investigator was one, and the investigator, knowing this, might dispense with the formality of asking for " permission" when his tests simply involved procedures which were commonplaces of clinical practice. He generally preferred to take the patient into his confidence over anything more elaborate, and this was where conscience and judgment became so important. Patients should be aware that at the best hospitals experimental work was carried out, not only for the advantage of the immediate sufferers but also for the benefit of mankind, and that they themselves owed incalculable advantages to work of this kind which had already been done on others. In actual fact patients rarely refused permission for investigations to be made on them, and many appreciated the extra attention which it involved. Opposition to experimental work was more likely to come from the physicians under whom the patients had been admitted, and from the nursing staff. There was one fundamental difference between the investigator and the physician. A good investigator must be interested primarily in his problem. The physician was concerned all the time with his patients. The physician was sometimes apt to be rather intolerant of the investigator, forgetting that the treatment he was prescribing was the result of experimental medicine, and that what he would have regarded as an unjustifiable experiment 20 years ago might have become one of his standard diagnostic or therapeutic procedures.

The basis of all successful experimentation was control of the conditions, and for much work in experimental medicine normal men and women were far more suitable than patients in hospital wards. In enlisting subjects, it was always a great help to have made the same experiment on oneself first and to be prepared if necessary to do so again. An experienced laboratory worker was probably the ideal experimental subject, though much useful work had been done with students, Service personnel, and also with groups of conscientious objectors during and just after the war.

Professor McCance concluded with the following words: "The medical profession has a responsibility not only for the care of the sick and for the prevention of disease but for the advancement of knowledge upon which both depend. This third responsibility can only be met by investigation and experiment, and from the nature of things it is always likely to remain the task of a few men and women specially gifted or trained for the purpose. Some of these people have in the past sacrificed considerable wealth for the mental satisfaction of their work. This may not have to be so in the future, but all such practitioners have a right to expect the fullest co-operation from their medical colleagues, from nurses and other assistants, from hospital managements, from patients and relatives, and from the community at large."

\section{MANCHESTER MEDICAL SOCIETY}

Dr. J. H. Kellgren, in discussing pain as an aid to diagnosis before the Section of Odontology of the Manchester Medical Society, said that the study of experimentally produced pain in normal human subjects had led to the development of a useful vocabulary for describing the different pains of disease and injury.

The simplest description of pain was in terms of its distribution and time-intensity curve. Thus a needle pricking the skin produced a momentary pain felt at a point which could be located with considerable accuracy, while cardiac angina was a continuous steady pain felt widely. within the chest and often spreading into the arm and jaw. There were three fundamentally different types of pain, subserved by different types of nerve fibre and accompanied by different reflex phenomenanamely, the aching-deep, the pricking-burning (first cutaneous), and the itching-stinging (second cutaneous) types.

\section{Toothache}

The teeth gave rise to only two forms of sensation-pressure and pain; thus behaving in this respect like all deep somatic tissues. Stimulation of carious teeth with an alternating current produced toothache of maximal intensity for a few minutes, the pain spreading widely in the face and head, with lacrimation and injection of the conjunctiva; later, the face felt stiff, and diffuse pain developed in the face and head. This was accompanied by deep tenderness of the muscles and periosteum and by cutaneous hyperalgesia, lasting for many hours, with abnormal sensitivity in the tooth to mechanical and electrical stimuli and to cooling. Anaesthesia of the sensitive tooth which was the source of pain invariably produced complete
relief. 
Pain, however, might be referred to the teeth from other structures such as the temporal and masseter muscles, or be due to irritation of the dental nerves somewhere along their courses to the brain. In these instances the tooth would probably not be so abnormally sensitive to stimuli, and anaesthetizing the tooth would have only a moderate and variable effect upon the pain. The temporomandibular joint may be another source of obscure pain felt deeply in the face, local analgesia of the joint helping to establish the source of pain.

The effect upon pain of alterations in the local circulation was also of interest; in the head the arteries were closely surrounded by pain nerves, and an abnormal amplitude of pulsation in the arterial tree caused severe pain as in migraine and the histamine headache. In these conditions arterial occlusion relieved the pain. Venous congestion might also have a marked effect upon pain in various conditions.

\section{Correspondence}

\section{Thiouracil and Vertigo Epidemica}

SIR,-Dr. C. Barrington Prowse in his paper (December 9. p. 1312) describes, under the heading of "a toxic effect of thiouracil hitherto undescribed," a complex of symptoms which rather suddenly appeared during the treatment of a case of thyrotoxicosis with thiouracil. The patient complained of difficulty in focusing her eyes; she had horizontal nystagmus, felt "light-headed," and stated that everything she looked at "seemed to be jumping about." After another four days she developed intense vertigo, and movements caused nausea and sickness. During the next three weeks she gradually improved.

I should like to draw your attention to the fact that the described illness in every regard is similar to cases observed and published in the Scandinavian countries under the heading of "vertigo epidemica" or "neurolabyrinthitis epidemica." Many observations of epidemic appearance of these symptoms - more or less prominent-have been made. The strong horizontal nystagmus was a characteristic phenomenon in the cases observed.

I suggest that the symptoms observed in Dr. Barrington Prowse's case have not been side-effects of thiouracil, but have been complicating vertigo epidemica, or neurolabyrinthitis epidemica.-I am, etc.,

Bispebjerg Hospital, Copenhagen.

E. Meulengracht.

\section{Tuberculosis as a Prescribed Disease}

SIR,--In your annotation (December 9, p. 1321), referring to my dissension from a recommendation of the Industrial Injuries Advisory Council that tuberculosis may be presumed to have been contracted at work up to two years after employment ceased, you state:

"He also considers that there should be a definite minimum qualifying period of six months' employment (the council's recommendation is six weeks) before the presumption is permitted that the infection was a result of previous employment."

I fear you have confused two issues. The council's recommendation of six weeks (with which I am in agreement) is in respect of a person who enters the nursing profession and contracts the disease within the first six weeks of such entry, because the consensus of medical opinion is that the period of incubation is six weeks, and therefore if a person shows the disease within the first six weeks the odds are that she acquired it before starting nursing.

As the council's recommendation at present stands, however, a nurse who shows the disease only after giving up her work need have worked no minimum qualifying period whatsoever before being eligible for benefit. Consequently, to take the extreme, a woman might enter the profession and be attached to a T.B. sanatorium for one day only, and 23 months afterwards contract the disease. As she can prove that for the period of one day (or even, say, one week) she was in "close and frequent contact" she will get the benefit of presumption. This, to my mind, is taking matters too far, which is why I ventured to dissent, and suggested that in order to obtain the benefit of presumption a person must have been in the nursing profession for a minimum period of six months.

I am aware that it is open to the Ministry to rebut the evidence, but $I$ am informed on the highest medical advice that rebuttal in the case of a person who can prove "close and frequent contact" would be extremely difficult. You will also appreciate that there is no quantum of time laid down in respect of "close and frequent contact."- I am, etc.,

London, S.W.1

T. A. E. LAYBORN.

\section{Truth about Tuberculosis}

SIR,-Please accept my thanks for the publicity you have given to the urgent need for a thorough overhaul of our tuberculosis service (e.g., December 16, p. 1373). For over 20 years I have tried to interest our profession in the idea that this disease of tuberculosis should and could be prevented and cured. We all know that many cases of tuberculosis do in time get cured by nature and not by any medical treatment, and yet no one has shown the profession and the public how it is done. I trust that you will force the Ministry of Health to inform the public what happens to all those persons who have had our sanatorium treatments. Let the public now be told the truth. Is it a fact that nearly $50 \%$ of all sanatorium patients have died from tuberculosis within five years of their admission? Do patients get admitted into our sanatoria when there is no chance of their either getting cured or having their disease permanently arrested ?-I am, etc.,

Itchingfield, near Horsham.

S. G. TIPPETT.

\section{Tuberculosis and the Health Service}

SIR,-When I read the headlines (taken from the Report of the Tuberculosis Group) in the Birmingham Mail, December 14, "Tuberculosis Provisions a 'National Scandal,' Sufferers Die Without a Chance in Life," and the headlines in the Daily Mail, December 15, "We Could End T.B. in a Generation, Doctor Points the Way," with the statement that "tuberculosis could be wiped out in a generation if there were more nurses, more beds, better after-care, more machines for mass radiography, and isolation of infected persons," I was shocked. Is there any truth? It was a relief to see your leader of December 16 (p. 1373), and, like many others, I wished that the following words from it had been given at least equal publicity: "Behind all the discontent and argument stand the facts that the mortality from tuberculosis is decreasing rapidly, that the number of new cases is increasing, that the average age at the time of first infection with tubercle bacilli is rising, and that the expectancy of life of tuberculous persons is lengthening."

If it were realized by the members of the general public that most of us have had tubercle and have recovered from it without knowledge or treatment, that the statements which I have italicized are true, and that the increased number of new cases has merely come from the application of more and more tests-i.e., mass radiography, etc.-they would be less scared by the propaganda of fear to which our tuberculosis experts are subjecting them. Cleveland has just completed its mass radiographic survey of 688,204 people with $23 x$-ray units, to find that it has $27 \%$ less tuberculosis cases than was estimated-i.e., about the same percentage as we have; but it has its slums, as we have.

I have carefully read through the Report of the Tuberculosis Group. Is not the dominant note self-interest? Read these recommendations :

"A chest clinic serving, as recommended, a population of 200,000 would need an establishment of one consultant, two assistant physicians, and an appropriate staff of registrar grade. The lay staff would comprise one almoner, five health visitors and clinic nurses, and five clerks."

"A large full-time clinic for chest diseases (all kinds) established in a general hospital will require its own permanent and specially trained auxiliary staff." 